\title{
Germline mutations and blood malignancy (Review)
}

\author{
YUPING GONG, JILI DENG and XIA WU \\ Department of Hematology, West China Hospital, Sichuan University, Chengdu, Sichuan 610041, P.R. China
}

Received February 27, 2020; Accepted October 1, 2020

DOI: $10.3892 / o r .2020 .7846$

\begin{abstract}
Germline mutations are congenital genetic mutations in germ cells that originate from sperm or ovum and are generally incorporated into every cell of the offspring's body. Somatic mutations are acquired genetic mutations that form under the influence of environmental factors during embryo formation and epigenetic development. Generally, only a portion of the cells in the human body have the same somatic mutations. Clinical detection of germline mutations is intended to determine inherited malignancies and identify high-risk families, and detection of somatic mutation is proposed to find targeted drugs, monitor tumor loading for guided therapy, and evaluate prognosis. Large-scale population cohort studies have shown that germline mutations are closely related to the occurrence, development, and prognosis of diseases. Patients with cancer-predisposition germline mutations can be used as sentinels in high-risk families. Traditional histopathology is no longer enough to identify types of cancers. Even within a particular type of tumor, there is great heterogeneity between internal molecules. The Pan-Cancer Research Program as well as other projects seek to use large quantities of data from different types of tumor research databases to carry out integrated analysis in order to establish potential non-tumor-specific tumor markers and targets by increasing the sample size to identify more molecular mechanisms. This review intends to summarize some of the relevant mechanisms underlying germline mutations in blood disorders.
\end{abstract}

\section{Contents}

\section{Introduction}

2.Studies on relevant mechanisms underlying blood disorder-related germline mutations: Germline CEBPA mutations

3. Germline $R U N X 1$ mutations

Correspondence to: Dr Yuping Gong, Department of Hematology, West China Hospital, Sichuan University, 37 GuoXue Xiang, Chengdu, Sichuan 610041, P.R. China

E-mail: gongyuping2010@aliyun.com

Key words: germline mutation, somatic mutation, cancer gene, blood malignancy, acute leukemia, myelodysplastic syndromes
4. Germline GATA2 mutations

5. DDX41/ETV6/ANKRD26 mutations

6. Germline mutations in ALL

7. Other germline mutations

8. Cancer-predisposing syndrome

9. Laboratory detection and clinical study of germline mutations

10. Discussion

\section{Introduction}

Over the past 10 years, the development of basic sequencing technologies, including next-generation sequencing (NGS) and single-cell sequencing, and research projects, such as the Human Genome Project (hg19), the The Cancer Genome Atlas (TCGA) Project, and the TCGA-Pan-Cancer Project, have made great progress. For example, TCGA includes 33 common cancers and over 11,000 tumor samples with data of about 2.5 petabytes. There are three parts including cell-of-origin patterns, oncogenic processes and oncogenic pathway in TCGA Pan-cancer Atlas. In 2016, one study found that $11.8 \%$ of male patients diagnosed with metastatic prostate cancer carry pathogenic germline DNA-repair gene mutations. The Gleason score in this group was statistically higher than that in non-metastasis patients and normal individuals (1). In another study of a Chinese cohort, it was also discovered that the mutation rate of the pathogenic germline BRCAl, $B R C A 2$ and $A T M$ genes in patients with non-metastatic prostate cancer was $7.55 \%$ totally, and that patients experienced metastasis at a rate of $9.68 \%$. The pathogenic germline ATM gene mutation was related to the early occurrence of prostate cancer $(\mathrm{P}=0.011)$ (2). In 2015, one study found the incidence of germline mutations in 1,120 child tumor patients to be $8.5 \%$, which was significantly different from the 1000 Genomes Project group (including autistic children) with a mutation rate of $0.6 \%$ to $1.1 \%$. The most common mutant genes were TP53, APC, BRCA2, NF1, PMS2, RB1, and RUNX1 (3). In 2018 , one study reported that the mutagenesis rate of germline mutations in 10,389 adult patients with 33 types of tumors was 8\%. BCRA1/2, ATM, RET, NF1, VHL, SDHB, and MET were found to be the most common mutant genes (4). Mutant gene detection in children and young patients who engaged in hematopoietic stem cell transplantation (HSCT) from 1999 to 2012 owing to aplastic anemia (AA) or myelodysplastic syndrome (MDS) showed that there was a 5.1\% (5/98) mutation rate in AA patients and $13.6 \%(15 / 110)$ rate in MDS patients, with 
most of the mutations being germline mutations. MDS-related mutant genes were found to include FANCA, GATA2, $M P L$, RTEL1, RUNX1, SBDS, TERT, TTNF2, and TP53 (5). In 2014, 59 cases in 17 families were identified through detection of mutations in the MDS/acute myeloid leukemia (AML) predisposition genes. Among them, there were five cases of pathological germline mutations in five pedigrees, and often, these familial inheritances progressed to MDS/AML with the occurrence of somatic mutations (6). This frequency rate is very high, even for families with high-risk breast cancer that can be explained with known genes, which warrants increased research attention. Germline genetic mutations are associated with the type of disease, characteristics of invasiveness and mechanism of inheritance. In breast cancer, the $T B X 3$ gene is associated with high breast cancer risk (an autosomal dominant model, rs2242442, $\mathrm{P}=0.01, \mathrm{OR}=0.76,95 \% \mathrm{CI}$ : 0.64-0.92) and decreased invasiveness of the tumor (7). Among the elderly, irrespective of the presence or absence of candidate-initiating genes, clonal hematopoiesis $(\mathrm{CH})$ is common. The whole-genome sequencing of 11,262 people found $\mathrm{CH}$ in 1,043 people, thereby elucidating the frequency of $\mathrm{CH}$. The acquired mutations of certain genes, such as TET2, DNMT3A, ASXL1, and PPMID, were identified to be strongly related to $\mathrm{CH}$; however, in most cases, no initiating genes have been identified (8).

Owing to the few tests and studies of germline mutations, which have predominantly focused on somatic mutant pathogenesis, the majority of studies concerning germline mutation are only at the statistical and bioinformatics level, Additionally, only a few genes related to disease mechanisms are included in the World Health Organization (WHO) classification (9). Germline mutations are the driving force underlying the genome and genetic disease evolution. The mutation rate in families increases with parental age, but the number of extra-age mutations increases more than twice across different families (8). Meta-analysis of 6,570 mutations showed that germline methylation affects the mutation rate, whereby, the mutation rate of single-cell divisions increases during embryo formation and primordial pelvis formation, and decreases significantly during sperm formation in adolescents (8). According to current theories, germline mutations in genes increase the susceptibility to tumors, while somatic mutations are the secondary reason for the occurrence of tumors. However, even for the same tumor type in different patients, it is still unclear whether the tumor has been caused by either only germline or somatic mutations or both. Somatic mutations are dynamic processes, which lead to the occurrence and development of diseases. The mechanisms underlying the initiation, maintenance, and progression of these mutations have yet not been clearly studied, which could be a research focus of future research.

\section{Studies on relevant mechanisms underlying blood disorder-related germline mutations: Germline $C E B P A$ mutations}

The CCAAT enhancer binding protein alpha (CEBPA) gene is located on chromosome 19 , and there are two types of this gene according to the WHO 2016 Classification (9). The CEBPA biallelic mutation has a germline mutation at the $3^{\prime}$ site and a somatic mutation at the 5 ' site, or two somatic mutations at the $5^{\prime}$ site. In 2008, one study first reported that patients with the same $C E B P A$ germline mutation appeared in the first proband's family, and somatic mutations at other sites led to the disease (10). Only biallelic CEBPA mutations indicate a robust prognosis (11). Usually, germline mutations occur at the N-terminal and somatic mutations occur at the C-terminal. Somatic mutations are unstable over the course of disease, and different mutant sites and mechanisms underlying mutations are detected as the disease progresses, which can be used to monitor tumor burden (12). Taskesen et al reported that the frequency of somatic mutations in AML was 7\% (13). Pabst et al showed that $11.1 \%$ of AML patients carry CEBPA germline mutations (10) and all are located at the N-terminal. The frequency of other gene co-mutations with biallelic $C E B P A$ mutations is low, and the prognosis is independent of NPM1 and/or FLT3-ITD mutations (13). Patients with biallelic mutations were found to have prolonged overall survival (OS), event-free survival (EFS), and relapse-free survival (RFS) than patients with single mutations, and researchers have proposed that AML patients with biallelic CEBPA mutations should be separated from AML patients with CEBPA mutations (12). Compared to the incidence of 7-9\% for somatic CEBPA mutations in sporadic cases, $83 \%$ of patients with $C E B P A$ germline mutations had somatic mutations at the C-terminal (14), which suggest that patients with CEBPA germline mutations should consider hematopoietic stem-cell transplantation (HSCT) early at the onset of the disease to replace mutant stem cells, improve the bone marrow hematopoietic microenvironment, and avoid the risk of C-terminal secondary somatic mutations as well as the relapse of leukemia (14). Ram et al reported that not all patients with germline mutations have a family history of cancer and germline mutations may not entirely be an issue (15). Therefore, patients without previous family histories should also be monitored. In a large-scale study of C-terminal mutant families, the complete penetrance rate was only $46 \%$ (16). Another study showed that GATA binding protein 2 (GATA2) gene mutation at the $\mathrm{ZF} 1$ site attenuated the activity of transcription factors that enhance $C E B P A$ regulation, indicating that $C E B P A$ double mutations downregulate the expression of certain target genes during the process of malignant tumor transformation (17).

\section{Germline $R U N X 1$ mutations}

Runt-related transcription factor $1(R U N X 1)$, expressed by the $R U N X 1$ gene located on chromosome 21, is a member of the RUNX transcription factor family, containing 138 amino acids with Runx homologous functional areas. RUNX1 has been categorized by the WHO 2016 Classification (9). Germline RUNX1 mutations are mainly associated with familial thrombopenia/AML. Ripperger et al reported that the father of a 13-year-old female proband was also diagnosed with AML and carried a similar $R U N X 1$ germline mutation (c.520>T, p. Arg174X). Both had abnormal karyotypes accompanied by different somatic mutations (18). It is possible to use these rare familial platelet disorder with predisposition to myeloid malignancy (FPD/MM)-related malignant tumors as a multiple-step model of MDS/AML. It was reported that an 18-year-old male with a negative parental gene test had a spontaneous 
$R U N X 1$ germline mutation and a secondary somatic nonsense mutation of exon 8 of the $R U N X 1$ gene (c.837G>A), which resulted in the premature stop of transcription in the exons of DNA binding the inhibition region with progression from congenital thrombopenia to acute granulocytic monocytic leukemia (19). In the absence of coexistence of other somatic mutations, gene germline co-mutations with somatic mutations produced a stronger dominant negative effect mutation in only one way (19). Churpek et al performed gene-panel tests on 264 cases, revealing that $67 \%$ of young cases $(<50$ years old) and asymptomatic $R U N X 1$ carriers had hematopoietic clone distortion (6). In an in vitro study, Antony-Debré et al induced pluripotent stem cells from two patients with RUNXI germline mutations, one of which was a monoallelic deletion of RUNX domain with only the presence of thrombopenia and the other mutation site was R174Q, which was a dominant negative-phase mutation with a nearly complete functional deletion, associated with thrombopenia and leukemia (20). A semi-deletion was found to lead to defects in erythrogenesis, megakaryocytic hematopoiesis and pre-platelet formation, as well as complete loss of activity causing the amplification of the granulocyte-monocyte chamber and the increase of genomic instability (20). The protein volume from $R U N X 1$ gene expression can explain the different phenotypes expressed by different $R U N X 1$ site mutations. In most cases, haploid dose deficiency only leads to thrombocytopenia, but a greater degree of gene deletion tends to occur in leukemia. Dowdy et al emphasized the pivotal role of RUNX1 in hematopoietic regulation. In their study, a full-length $R U N X 1$ protein expressed by the $R U N X 1$ gene in mice was established with a germline point mutation at HTY350-352AAA (21). The mutant mice could bypass the lethal embryo and live to adulthood without pathogenic changes in hematopoietic stem cells, but there were multi-line hematopoietic differentiation changes in adulthood with hematopoietic directional progenitor cell growth control defects. Downregulation of B line lymphocytes and myeloid lines along with delaying megakaryocytic and erythroid development and maturation were present (21). These results showed that the germline $R U N X 1$ gene also plays a regulatory role in embryogenesis, final hematopoiesis, and differentiation of multiple hematopoietic lines.

\section{Germline GATA2 mutations}

Clinical manifestations of congenital GATA2 deficiency are non-tuberculosis mycobacterial infections, opportunistic infections, severe monocyte, natural killer (NK) cell, and B cell defects, and progress from hypoplastic MDS to myeloid leukemia. Compared with non-progressive MDS, the germline GATA2 mutation in progressive MDS had a higher carrying rate $(15 \%, 13: 85$ vs. $4 \% 15: 341, \mathrm{P}<0.01)$, older age $(12.3$ vs. 10.3 years, $\mathrm{P}<0.001)$ and a larger proportion of chromatid 7 ( 70 vs. $11 \%, \mathrm{P}<0.01$ ), and $71 \%$ of cases had no blood disorder family history (22). Most of the studies on the mechanisms underlying GATA2 germline mutations have revealed a single mutation site, such as germline point mutation p.Arg396Gln, leading to the loss of GATA2 function, which affects the binding ability of the DNA region and inability to maintain the undifferentiated characteristics of hematopoietic stem cells or mature progenitor cells (23). Wild-type GATA2 can regulate its transcription through the special domain of $2.4 \mathrm{~kb}$ from IS TSS (a transcription structure region), but the mutant type cannot regulate transcription correctly. A functional study of the three most common germline GATA2 mutations (gT354M, gR396Q, and gR398W), showed that the intensity of binding and the ability to activate mutant DNA decreased (24). These results may be based on the complete amino acid deletion of the structural integrity of the ZF2 domain of DNA-bound arginine or zinc finger proteins. Mutants of T354M or C373R bind more closely to hematopoietic differentiation factor PU.1 and interfere with differentiation, and some mutations will make the cells progress toward granulocytic diseases. The normal physiological activities of genes are closely regulated in the processes of replication, transcription, and translation. With this, cell type-specific enhancers strictly regulate the physiological activity of GATA2. The $9.5 \mathrm{bp}$ enhancer of the GATA2 gene produces a variety of conserved cis elements, and the germline mutation of the cis element is pathogenic. Soukup et al established a mouse model with a germline GATA2 enhancer mutation (25). The multi-motif results in embryonic lethality, but the single-nucleotide ET motif mutation can bypass embryo lethality and live to adulthood while also maintaining normal steady-state hematopoiesis. However, the mutation of the ET motif makes hematopoietic stem cells and progenitor cells lose their effects under different stresses. Overall, the results showed that single-nucleotide mutations have disease tendencies while retaining development activities, inactivating the regeneration ability of enhancers, destroying the hematopoietic regulation mechanism, leading to hematopoietic failure (25). Abnormal clone hematopoietic formation can be observed in both MDS patients with symptomatic germline GATA2 mutations and patients with peripheral cytopenia but no obvious morphological evidence of dysplasia in bone marrow (26). The hypocellular state may be a pre-MDS stage. A total of 14/28 (29\%) of patients with germline GATA2 deletions had heterogeneous and somatic ASXL1 mutations, of which $4 / 5$ had proliferating chronic myelomonocytic leukemia (27). GATA2 with the ASXL1 mutation is related to an unfavorable prognosis. However, whether the two are synergistic cannot be identified. The ASXL transcriptional regulator 1 ( $A S X L 1)$ mutation transforms into myeloid disease in patients with germline GATA2 mutations, especially in terms of progressing to chronic myelomonocyticleukemia (CMML). GATA2 germline mutation patients with ASXL1 somatic mutation are younger, almost all of them are female (13/14), and each has a high risk of progressing to CMML (27). Early allogenic stem cell transplantation can benefit patients before they progress to AML or CMML. The status of GATA2 does not affect the prognosis of biallelic CEBPA/FLT-ITD negative patients (28).

\section{DDX41/ETV6/ANKRD26 mutations}

In the 2016 edition of the WHO Classification, myeloid neoplasms with germline predisposition was considered a major sectional change, specifically including genes $D D X 41$, ANKRD26, ETV6 and GATA2 (9). DEAD-box helicase 41 (DDX41) is composed of 17 exons and is located on chromosome 5 (5q35.3). The majority of germline mutations that occur in $D D X 41$ are frameshift mutations that lead to loss of function 
in DDX41 acting as a tumor suppressor (29). Quesada et al found only TP53 $(\mathrm{n}=11,32 \%)$, ASXL transcriptional regulator $1(A S X L 1)(\mathrm{n}=8,24 \%)$, and Janus kinase $2(J A K 2)(\mathrm{n}=4$, $12 \%$ ) were recurrent with $D D X 41$ gene mutations in myeloid neoplasm disease (30). Germline mutations in ankyrin repeat domain 26 (ANKRD26) and ETS variant transcription factor 6 (ETV6) have been reported with inherited thrombocytopenia (IT) and platelet disorders with germline predisposition to myeloid neoplasia (31). These patients are characterized by early onset or are vulnerable to attack by other somatic mutant genes with such a genetic background. Many cases have been initially misdiagnosed as Immune thrombocytopenia purpura (ITP) or sporadic MDS. Progression to MDS/AML may be associated with bi- or pancytopenia, multi-lineage dysplasia, acquisition of cytogenetic abnormalities, or somatic mutations, indicating clonal progression and/or bi-allelic mutations (31). Perez Botero et al first reported a case of chronic myelomonocytic leukemia-1 in a patient with a germline ANKRD6 mutation diagnosed with thrombocytopenia 2 (THC2), a non-syndromic, autosomal dominant thrombocytopenia (32). Targeted NGS of ETV6 performed in germline DNA samples from 4,405 children with acute lymphoblastic leukemia (ALL) determined 31 rare ETV6 variants that were potentially related to ALL predisposition. In children harboring these mutations, ALL had distinct clinical features, such as older age at diagnosis, which indicated a unique mechanism of leukemia pathogenesis related to these ETV6 variants. The authors estimated that approximately $1 \%$ of patients with childhood ALL potentially carry highly penetrant ETV6 variants (33).

\section{Germline mutations in ALL}

Germline mutations also include lymphoid neoplasms that are not only specific to myeloid tumors. Many gene mutations have been reported to be associated with hematological malignancies, especially in children with ALL, such as mutations in TP53, protein tyrosine phosphatase non-receptor type 11 (PTPN11) (34), ATRX chromatin remodeler (ATRX) (35), IKAROS family zinc finger 1 (IKZFl) (36), ETS-related gene $(E R G)$, homeobox D4 (HOXD4), and SH2B adaptor protein $3(\mathrm{SH} 2 \mathrm{~B} 3)$. Here, we describe certain disease-related mechanisms and associated novel research progress. In a cohort study, somatic mutations affecting the RAS pathway were found in relapse ALL patients, along with epigenetic and developmental alterations. However, germline mutations also influence DNA-repair pathways (37). Germline heterozygous $I K Z F 1$ gene mutations cause dysgammaglobulinemia; hematologic abnormalities, including B-cell defects; and autoimmune diseases (36). The germline $E R G$ mutation is required for definitive hematopoiesis, adult hematopoietic stem cell function, and the maintenance of normal peripheral blood platelet numbers (38). The germline PTPN11 gene (encoding a Shp2 protein) has also been recognized as the cause of such a deadly disease owing to the occurrence of germline mutations at the interface of the PTP and SH2 domains (39). Functional analysis of the murine Hoxd4 homolog uncovered that mutant HOXD4 protein had lower transcriptional activity than wild-type protein in vitro, resulting in a partial loss of function, which might be involved in childhood ALL (40). Research has also determined that loss of $\mathrm{SH} 2 \mathrm{~B} 3$ increases Janus kinase, a signal transducer and activator of transcription signaling, promoting lymphoid cell proliferation and accelerating leukemia development in a mouse model of $\mathrm{NOTCH1-induced}$ ALL (41). Li-Fraumeni syndrome (LFS) is characterized as an autosomal dominant cancer predisposition disorder caused by germline TP53 gene mutations. Germline TP53 variants in childhood hypodiploid ALL suggest another manifestation of LFS. Qian et al identified 49 unique non-silent, rare TP53 coding variants in $77(2.0 \%)$ of 3,801 patients sequenced, of which 22 variants were classified as pathogenic, suggesting gene loss of function. TP53 pathogenic variants were significantly over-represented in ALL compared with non-ALL controls, characterized by older ALL diagnosis, more likely to have hypodiploid ALL, inferior EFS, short OS, and higher risk of second malignant neoplasms (42). For B-ALL patients with a germline TP53 c.818G >A (p.R273H) mutation, Chimeric antigen receptor (CAR) T-cell therapy may be an alternate choice as traditional chemotherapy and allogenic stem cell transplantation (SCT) are not effective strategies for those patients with adverse outcomes (43).

\section{Other germline mutations}

Hamadou et al reported a germline ASXL transcriptional regulator 1 ( $A S X L 1)$ deletion in p.Arg402Gln for the first time in a case of non-Hodgkin lymphoma, whereby bioinformatics analysis predicted potentially harmful effects (44). Seiter et al performed NGS using samples of AML, which was diagnosed as MDS transformed by both a 46-year-old son and his 75-year-old father, and found c.2957A $>\mathrm{G}$ in both blood and non-blood tissues. Mutations were no longer detected in peripheral blood after stem cell transplantation (45). Furthermore, it was reported that the germline deletion mutation of $8 \mathrm{bp}$ of intron 3 of the telomerase reverse transcriptase (TERT) gene tended to have $\mathrm{CH}$ abnormity $\left(\mathrm{P}=7.4 \times 10^{-12}, \mathrm{OR}=1.37\right)$ (46). A Chinese family with AML exhibited autosomal dominant inheritance, and 11 patients of four generations of this family carried the transglutaminase 6 (TGM6) gene deletion mutation (c.1550T>G, p.L517W) (47). The amino acid alterations affecting the activation of TGM6 in a highly conserved region may be involved in the development of disease. Pauli et al reported a 6-year-old boy with Noonan syndrome (NS) suffering from B-cell precursor acute lymphoblastic leukemia (BCP-ALL) with the germline PTPN11 mutation (34). Moreover, Hahn et al sequenced the exons of 144 patients with MDS and those with other hematological malignancies, demonstrating that the carrying rate of five genes (TET2, MET, GATA2, ASXL1, NOTCH1) was 1.5- to 6.0-fold higher in patients than in the control group (ExAC database or control group), such as NOTCH1 R912W, with a 6.5-fold higher carrying rate than that in controls (48). AML patients with somatic mutations, compared with the normal population before the occurrence of disease, had a higher frequency of mutations and VAF, while the mutations of specific genes were more diverse (49). This indicated that there are differences and specificities in terms of whether the disease occurs or not in cases of both somatic and germline mutations. Although inheritance of AML is rare, the results obtained for these families could help describe the potential pathogenesis of more common and sporadic cases. To a large extent, tumor progression is influenced by genetic polymorphisms carried by germline cells. There was an association between the diversity in 
germline gene mutations and somatic events (including specific tissue tumorigenesis and oncogene formation) (50). In the same disease category, different gene mutations can represent different disease subtypes and highlight various clinical characteristics. Bluteau et al sequenced the whole exons of skin fibers of 179 patients with non-hereditary bone marrow failure syndrome from 2002 to 2016 (51) and found that the new germline mutation of sterile alpha motif domain containing 9 like (SAMD9L) was present at a rate of $5.6 \%(10 / 179)$, followed by telomerase RNA component $($ TERC) at 5.0\% (9/179) and GATA2 at $3.9 \%$ (7/179). Unlike clearly diagnosed hereditary bone marrow failure syndrome, different germline mutations and inexplicitly genetic bone marrow failure in patients represent different disease types such as MDS1 and EVI1 complex locus protein EVI1 (MECOM), which is a subgroup of severe aplastic anemia requiring urgent HSCT. In these cases, thorough and broader genetic testing is necessary, including that of regulatory regions, introns, and other splicing regions. According to the classification of diseases based on cytogenetics and molecular biology, the diagnosis and targeted treatment of hematological diseases will be carried beyond the traditional classification of diseases, and individualized treatment along with precision medicine will achieve further progress. We have summarized all the mutant sites in this article and their related references in Table I.

\section{Cancer-predisposing syndrome}

Cancer-predisposing syndrome (CPS) is the occurrence of certain human malignant tumors with familial aggregation, wherein multiple members of a family have the same tumor or several tumors. The syndrome is characterized by early onset, a high degree of malignancy, and multiple recurrences. Multiple CPS have been identified, such as LFS, neurofibromatosis type 1, APC-related adenomatous polyposis, Beckwith-Wiedemann syndrome, multiple endocrine neoplasia 1, ataxia telangiectasia, RUNX1 deficiency, Fanconi anemia, Bloom syndrome, and PTEN hamartoma tumor syndrome (52). To date, BMF syndrome, telomere biology disorders, neurofibromatosis, Noonan syndrome or Noonan syndrome-like disorders, and Down syndrome have been included in the WHO 2016 revision of myeloid neoplasms and the acute leukemia classification (9). Variable and incomplete penetrance could not only explain why inherited diseases are occasionally transmitted through unaffected parents, but also why clinically healthy individuals can carry potentially pathogenic variants without expressing features of the disease. New sequencing techniques and karyotype analysis are more helpful in the diagnoses of these diseases, which have already been reported to be linked to one or multiple genetic mutations. As shown in Table I, specific one-gene mutations correspond to relative disease phenotypes. However, many genetic mutations have not been reported to specifically be associated with blood malignancy diseases, or these diseases are caused due to the involvement of multiple genes. This includes mutations of the Fanconic anemia $(F A N C)$ genes, such as FANCA, FANCD and FANCW in Fanconi anemia, TP53 in LFS, and Cbl proto-oncogene $(C B L)$ in CNL; however, how these mutations impact tumorigenesis needs to be determined. For children, in particular, early onset malignancies with a positive family history should be listed separately for diagnosis and treatment. Epigenetic mechanisms and alterations in DNA-repair genes warrant further investigation and may be promising treatment targets.

\section{Laboratory detection and clinical study of germline mutations}

In order to avoid the contamination of normal DNA with tumor cell DNA, bone marrow and peripheral blood are not considered to be suitable specimen sources when detecting germline mutations in leukemia patients. Skin biopsies are regarded as the 'gold standard', while hair and nails are relatively robust sources followed by oral epithelial cells and saliva; the quality and quantity of the DNA obtained from hair and nail samples are inadequate (53). Therefore, we propose that the peripheral blood of healthy relatives of probands can be used as a relatively uncontaminated and abundant source of DNA for detection of the same germline mutations as those in patients diagnosed with hematological diseases for the first time, enabling the detection of concomitant secondary somatic mutations in patients. Drazer et al believed that the use of non-hematopoietic stem cells for genetic testing, such as dermal tissue fibroblasts, could be beneficial in avoiding misdiagnosis of gene mutations in the laboratory, owing to the lower frequency of allele mutations in blood corpuscles (54). In addition, it is important to identify somatic or germline mutations by sequencing of the secondary tissue or parental genes. Family history or physical examination sometimes cannot fully predict the existence of germline mutations. In particular, for those diseases caused by multiple genetic mutations, genes that are damaged or seem to have disappeared after chemotherapy are suggested to have harbored somatic mutations, while the remaining genes are suggested to have had germline mutations. The prognostic impact of the presence of gene mutations before and after complete remission also needs to be analyzed. Even when considering the same gene, the phylogenetics may occur in a reciprocal fashion (50). NGS of the tumor tissue can also be used to identify patients with high-risk hereditary hematologic malignancy syndrome. Drazer et al reported that 74/360 (21\%) healthy individuals carried mutations in genes that were pathogenic or potentially pathogenic, and eventually 25 pathological mutations with VAF $>40 \%$ were identified, of which $6 / 25$ (24\%) were germline-derived pathogenic mutations. However, even if clear family history was available, germline mutant testing did not necessarily lead to valid results (54). Király et al tested the members of three families (including eight genes: RUNX1, CEBPA, GATA2, ANKRD26, ETV6, DDX41, TERC or TERT, SRP72) who showed a significant link with myeloid malignancies in nine patients and reported that, to date, quite a few disease-related genes have not been investigated for their association with morbidity and that there were technical limitations in performing such studies. Whole-exome sequencing or whole-genome sequencing may be necessary for these families (55).

\section{Discussion}

A number of solid tumors show a definite familial inheritance pattern with gene mutations. The onset of hereditary syndromes in childhood is the main clinical manifestation. 
Table I. Germline mutations discussed in this review.

\begin{tabular}{|c|c|c|c|c|c|}
\hline \multirow[b]{2}{*}{ Mutant genes [symbol (full name)] } & \multicolumn{2}{|c|}{ Mutant sites } & \multirow{2}{*}{$\begin{array}{l}\text { Disease } \\
\text { hematologic } \\
\text { phenotype }\end{array}$} & \multirow{2}{*}{$\begin{array}{c}\text { Other } \\
\text { phenotypes }\end{array}$} & \multirow[b]{2}{*}{ EXAC } \\
\hline & c. & p. & & & \\
\hline$A S X L 1$ & c. $1205 \mathrm{G}>\mathrm{A}$ & R402Q & NHL & Bohring-Optiz & NR \\
\hline (additional sex combs like 1) & c. $2957 \mathrm{~A}>\mathrm{G}$ & N986S & MDS trans AML & syndrome & NR \\
\hline $\begin{array}{l}\text { TERT } \\
\text { (telomerase reverse transcriptase) }\end{array}$ & c.1280826_128083 & NR & Predisposition to & Thyroid cancer & NR \\
\hline TGM6 (transglutaminase) & 3delAGCCCACC & & $\mathrm{CH}$ & & \\
\hline PTPN11 & c. $1550 \mathrm{~T} 4 \mathrm{G}$ & L517W & AML & Sanger-Brown's ataxia & NR \\
\hline $\begin{array}{l}\text { (protein tyrosine phosphatase, } \\
\text { non-receptor type } 11 \text { ) }\end{array}$ & c. $922 \mathrm{~A}>\mathrm{G}$ & N308D & BCP-ALL & Noonan syndrome & NR \\
\hline \multirow{6}{*}{$\begin{array}{l}\text { TET2 } \\
\text { (tet methylcytosine dioxygenase } 1 \text { ) }\end{array}$} & NR & Y867H & MDS & NR & 0.00693 \\
\hline & & P1723S & & & 0.005895 \\
\hline & & L1721W & & & 0.00008987 \\
\hline & & H1778R & & & NR \\
\hline & & Q1084P & & & 0.002635 \\
\hline & & V1718L & & & 0.002964 \\
\hline NOTCH1 (notch 1) & NR & R912W & MDS & $\begin{array}{l}\text { Esophageal, stomach, } \\
\text { cervical and colorectal } \\
\text { cancer }\end{array}$ & NR \\
\hline \multirow{7}{*}{$\begin{array}{l}\text { RUNXI } \\
\text { (runt-related transcription factor } 1 \text { ) }\end{array}$} & c. $520>\mathrm{T}$, & $\mathrm{R} 174 \mathrm{X}$ & AML & NR & NR \\
\hline & c. $837 \mathrm{G}>\mathrm{A}$ & NR & & & NR \\
\hline & c. $952 \mathrm{~T}>\mathrm{G}$ & S318A & & & 0.0007742 \\
\hline & $\begin{array}{l}\text { c.1098-1103 } \\
\text { delCGGCAT, }\end{array}$ & I366-367del & & & 0.00002871 \\
\hline & c. $620 \mathrm{G}>\mathrm{A}$ & R207Q & & & 0.0002065 \\
\hline & c. $155 \mathrm{~T}>\mathrm{A}$ & NR & & & NR \\
\hline & $\begin{array}{l}\text { c.554_560 } \\
\text { delAAGTCGC }\end{array}$ & M52K & & & NR \\
\hline $\begin{array}{l}\text { CEBPA [CCAAT/enhancer } \\
\text { binding protein }(\mathrm{C} / \mathrm{EBP}), \text { alpha] }\end{array}$ & c.584_589dup & NR & AML & & NR \\
\hline \multirow[t]{5}{*}{ GATA2 (GATA binding protein 2) } & & $\mathrm{T} 354 \mathrm{M}$ & AML & Cytopenia, bone & NR \\
\hline & & R396Q & & marrowfailure, severe & NR \\
\hline & & R398W & & immunodeficiency & NR \\
\hline & & A164T & & & 0.2056 \\
\hline & & A161A & & & 0.009627 \\
\hline \multirow[t]{3}{*}{$M E T$ (met proto-oncogene) } & & E168D & MDS & NR & 0.000008321 \\
\hline & & $\mathrm{R} 988 \mathrm{C}$ & & & 0.002853 \\
\hline & & T1010I & & & 0.00001662 \\
\hline TP53 (tumor suppressor protein 53) & c. $818 \mathrm{G}>\mathrm{A}$ & $\mathrm{R} 273 \mathrm{H}$ & ALL & Li-Fraumeni syndrome & NR \\
\hline HOXD4 (homeobox D4) & c. $242 \mathrm{~A} 4 \mathrm{~T}$ & $\mathrm{E} 81 \mathrm{~V}$ & ALL & Bone disease & NR \\
\hline
\end{tabular}

ExAC, The Exome Aggregation Consortium (http://exac.broadinstitute.org/. ExAC data is available in the gnomAD browser or can be downloaded from gs://gnomad-public/legacy). NR, not reported or not found in the EXaC database; NHL, non-Hodgkin lymphoma; AML, acute myeliod leukemia; ALL, acute lymphoblastic leukemia; MDS, myelodysplastic syndrome; CH, clonal hematopoiesis; BCP-ALL, B-cell precursor acute lymphoblastic leukemia; g., genomic sequence; c., coding DNA sequence; p., protein.

Germline mutations in adults do not impact their growth and development but do affect hematopoietic generation and differentiation. Furthermore, the detection of these mutations can aid in the identification of certain special disease types, guide risk prognosis stratification, and inspire appropriate treatment plans that can further lead to improving the quality 
of life of patients. During the genetic screening of potential related donors for HSCT, it is very important to avoid using a mutation-positive related donor to prevent donor-derived MDS/AML or other hematologic malignancy. Xiao et al reported that a 36-year-old male [donor with the same CEBPA germline mutation (584-589dup)] underwent transplantation and relapsed after 15 months. No somatic mutation was detected in the donor, and complete chimerism was detected in the recipient after recurrence when considering donor-derived leukemia (56). Galera et al reported three families with GATA2 germline mutations undergoing transplantations. Of them, a 21-year-old male $(46, \mathrm{XY},-7,13)$ with an NRAS somatic mutation received cells with the same GATA2 germline mutation from his 64-year-old mother. He was diagnosed with donor-derived MDS three years later (57). Donors with germline mutations may have no clinical manifestation, but in the recipient, the same germline mutation re-enters the same recipient environment, which may trigger a donor-derived somatic mutation and lead to the recurrence of the disease or new emergence of the donor-derived disease. Early molecular recognition of these mutations can provide molecular and genetic support to ensure the success of transplantation and avoid disease recurrence.

Second, in addition to the medical value of determining germline mutations for affected patients, attention should be paid to the physical and mental health of the affected family members. Clinical symptom monitoring, genetic screening, disease diagnosis, and counseling should be carried out for these affected family members, as well as long-term pre-disease status monitoring. In addition, diseases are also influenced by epigenetics and penetrance rates, so more attention should be paid to the psychology of family members, ensuring there is minimal cause of anxiety, panic, excessive examination or even excessive treatment, as well as ensuring there is minimal wastage of social resources.

Finally, with the development of detection technology and increase in false-positive rates brought about by the improvement in specificity, clinicians should make accurate judgments of the needs of affected family members and the type of genetic tests that should be performed, formulate more normative guidelines, and conserve medical and social resources.

\section{Acknowledgements}

The authors declare that all the information in this article comes from the real information in the literature.

\section{Funding}

There is no funding for this article.

\section{Availability of data and materials}

All information included in this review is documented by recent and valid references.

\section{Authors' contributions}

JD and YG conceptualized the study. JD and XW collected the reference. JD and YG wrote, reviewed, and edited the manuscript. All authors read and approved the final version of the manuscript.

\section{Ethics statement and consent to participate}

This article does not contain any studies with human participants or animals performed by any of the authors.

\section{Patient consent for publication}

Not applicable.

\section{Competing interests}

The authors declare that they have no conflict of interest.

\section{References}

1. Pritchard CC, Mateo J, Walsh MF, De Sarkar N, Abida W, Beltran H, Garofalo A, Gulati R, Carreira S, Eeles R, et al: Inherited DNA-repair gene mutations in men with metastatic prostate cancer. N Engl J Med 375: 443-453, 2016.

2. Wu J, Gu W, Qin X, Lin G, Dai B, Zhu Y and Ye D: Study on BRCA $1 / 2$ and ATM germline mutations in the Chinese prostate cancer patients. Chin Oncol 28: 584-589, 2018 (In Chinese).

3. Bardai A, Overwater E and Aalfs CM: Germline mutations in predisposition genes in pediatric cancer. N Engl J Med 374: 1390-1391, 2016.

4. Huang KL, Mashl RJ, Wu Y, Ritter DI, Wang J, Oh C, Paczkowska M, Reynolds S, Wyczalkowski MA, Oak N, et al: Pathogenic germline variants in 10,389 adult cancers. Cell 173: 355-370, 2018.

5. Keel SB, Scott A, Sanchez-Bonilla M, Ho PA, Gulsuner S Pritchard CC, Abkowitz JL, King MC, Walsh T and Shimamura A: Genetic features of myelodysplastic syndrome and aplastic anemia in pediatric and young adult patients. Haematologica 101: 1343-1350, 2016.

6. Churpek JE, Pyrtel K, Kanchi KL, Shao J, Koboldt D, Miller CA, Shen D, Fulton R, O'Laughlin M, Fronick C, et al: Genomic analysis of germ line and somatic variants in familial myelodysplasia/acute myeloid leukemia. Blood 126: 2484-2490, 2015.

7. Göhler S, Da Silva Filho MI, Johansson R, Enquist-Olsson K, Henriksson R, Hemminki K, Lenner P and Försti A: Functional germline variants in driver genes of breast cancer. Cancer Causes Control 28: 259-271, 2017.

8. Rahbari R, Wuster A, Lindsay SJ, Hardwick RJ, Alexandrov LB, Al Turki S, Dominiczak A, Morris A, Porteous D, Smith B, et al: Timing, rates and spectra of human germline mutation. Nat Genet 48: 126-133, 2016.

9. Arber DA, Orazi A, Hasserjian R, Thiele J, Borowitz MJ, Le Beau MM, Bloomfield CD, Cazzola M and Vardiman JW: The 2016 revision to the world health organization classification of myeloid neoplasms and acute leukemia. Blood 127: 2391-2405, 2016.

10. Pabst T, Eyholzer M, Haefliger S, Schardt J and Mueller BU: Somatic CEBPA mutations are a frequent second event in families with germline CEBPA mutations and familial acute myeloid leukemia. J Clin Oncol 26: 5088-5093, 2008.

11. Li HY, Deng DH, Huang Y, Ye FH, Huang LL, Xiao Q, Zhang B Ye BB, Lai YR, Mo ZN and Liu ZF: Favorable prognosis of biallelic CEBPA gene mutations in acute myeloid leukemia patients: A meta-analysis. Eur J Haematol 94: 439-448, 2015.

12. Tawana K, Wang J, Renneville A, Bödör C, Hills R, Loveday C, Savic A, Van Delft FW, Treleaven J, Georgiades P, et al: Disease evolution and outcomes in familial AML with germline CEBPA mutations. Blood 126: 1214-1223, 2015.

13. Taskesen E, Bullinger L, Corbacioglu A, Sanders MA, Erpelinck CA, Wouters BJ, van der Poel-van de Luytgaarde SC, Damm F, Krauter J, Ganse A, et al: Prognostic impact, concurrent genetic mutations, and gene expression features of AML with CEBPA mutations in a cohort of 1182 cytogenetically normal AML patients: Further evidence for CEBPA double mutant AML as a distinctive disease entity. Blood 117: 2469-2475, 2011. 
14. Stelljes M, Corbacioglu A, Schlenk RF, Döhner K, Frühwald MC Rossig C, Ehlert K, Silling G, Müller-Tidow C, Juergens H, et al: Allogeneic stem cell transplant to eliminate germline mutations in the gene for CCAAT-enhancer-binding protein $\alpha$ from hematopoietic cells in a family with AML. Leukemia 25: 1209-1210, 2011.

15. Ram J, Flamm G, Balys M, Sivagnanalingam U, Rothberg PG, Iqbal A, Myers JR, Corbett A, Ashton JM and Mendler JH: Index case of acute myeloid leukemia in a family harboring a novel CEBPA germ line mutation. Blood Adv 1: 500-503, 2017.

16. Nanri T, Uike N, Kawakita T, Iwanaga E, Mitsuya H and Asou N: A family harboring a germ-line N-terminal C/EBPalpha mutation and development of acute myeloid leukemia with an additional somatic C-terminal C/EBPalpha mutation. Genes Chromosomes Cancer 49: 237-241, 2010

17. Greif PA, Dufour A, Konstandin NP, Ksienzyk B, Zellmeier E, Tizazu B, Sturm J, Benthaus T, Herold T, Yaghmaie M, et al: GATA2 zinc finger 1 mutations associated with biallelic CEBPA mutations define a unique genetic entity of acute myeloid leukemia. Blood 120: 395-403, 2012.

18. Ripperger T, Steinemann D, Göhring G, Finke J, Niemeyer CM, Strahm B and Schlegelberger B: A novel pedigree with heterozygous germline RUNX1 mutation causing familial MDS-related AML: Can these families serve as a multistep model for leukemic transformation? Leukemia 23: 1364-1366, 2009.

19. Schmit JM, Turner DJ, Hromas RA, Wingard JR, Brown RA, Li Y, Li MM, Slayton WB and Cogle CR: Two novel RUNX1 mutations in a patient with congenital thrombocytopenia that evolved into a high grade myelodysplastic syndrome. Leuk Res Rep 4: 24-27, 2015.

20. Antony-Debré I, Manchev VT, Balayn N, Bluteau D, Tomowiak C, Legrand C, Langlois T, Bawa O, Tosca L and Tachdjian G: Level of RUNX1 activity is critical for leukemic predisposition but not for thrombocytopenia. Blood 125: 930-940, 2015.

21. Dowdy CR, Frederick D, Zaidi SK, Colby JL, Lian JB, van Wijnen AJ, Gerstein RM, Stein JL and Stein GS: A germline point mutation in RUNX1 uncouples its role in definitive hematopoiesis from differentiation. Exp Hematol 41: 980-991, 2013

22. Wlodarski MW, Hirabayashi S, Pastor V, Starý J, Hasle H, Masetti R, Dworzak M, Schmugge M, van den Heuvel-Eibrink M, Ussowicz M, et al: Prevalence, clinical characteristics, and prognosis of GATA2-related myelodysplastic syndromes in children and adolescents. Blood 127: 1387-1397, 2016.

23. Cortés-Lavaud X, Landecho MF, Maicas M, Urquiza L, Merino J, Moreno-Miralles I and Oder MD: GATA2 germline mutations impair GATA2 transcription, causing haploinsufficiency: Functional analysis of the p.Arg396Gln mutation. J Immunol 194: 2190-2198, 2015

24. Chong CE, Venugopal P, Stokes PH, Lee YK, Brautigan PJ, Yeung DT, Babic M, Engler GA, Lane SW, Klingler-Hoffmann $\mathrm{M}$, et al: Differential effects on gene transcription and hematopoietic differentiation correlate with GATA2 mutant disease phenotypes. Leukemia 32: 194-202, 2018.

25. Soukup AA, Zheng Y, Mehta C, Wu J, Liu P, Cao M, Hofmann I, Zhou Y, Zhang J, Johnson KD, et al: Single-nucleotide human disease mutation inactivates a blood-regenerative GATA2 enhancer. J Clin Invest 129: 1180-1192, 2019

26. McReynolds LJ, Yang Y, Wong HY, Tang J, Zhang Y, Mulé MP Daub J, Palmer C, Foruraghi L, Liu Q, et al: MDS-associated mutations in germline GATA2 mutated patients with hematologic manifestations. Leuk Res 76: 70-75, 2019.

27. West RR, Hsu AP, Holland SM, Cuellar-Rodriguez J and Hickstein DD: Acquired ASXL1 mutations are common in patients with inherited GATA2 mutations and correlate with myeloid transformation. Haematologica 99: 276-281, 2014.

28. Green CL, Tawana K, Hills RK, Bödör C, Fitzgibbon J, Inglott $S$, Ancliff P, Burnett AK, Linch DC and Gale RE: GATA2 mutations in sporadic and familial acute myeloid leukaemia patients with CEBPA mutations. Br J Haematology 161: 701-705, 2013.

29. Cheah JJ, Hahn CN, Hiwase DK, Scott HS and Brown AL: Myeloid neoplasms with germline DDX41 mutation. In J Hematol 106: 163-174, 2017.

30. Quesada AE, Routbort MJ, DiNardo CD, Bueso-Ramos CE, Kanagal-Shamanna R, Khoury JD, Thakral B, Zuo Z, Yin CC, Loghavi S, et al: DDX41 mutations in myeloid neoplasms are associated with male gender, TP53 mutations and high-risk disease. Am J Hematol 94: 757-766, 2019.

31. Galera P, Dulau-Florea A and Calvo KR: Inherited thrombocytopenia and platelet disorders with germline predisposition to myeloid neoplasia. Int J Lab Hematol 41: 131-141, 2019.
32. Perez Botero J, Oliveira JL, ChenD, Reichard KK, Viswanatha DS, Nguyen PL, Pruthi RK, Majerus J, Gada P, Gangat N, et al: ASXL1 mutated chronic myelomonocytic leukemia in a patient with familial thrombocytopenia secondary to germline mutation in ANKRD26. Blood Cancer J 5: e315, 2015.

33. Romero D: Haematological cancer: ETV6 germline mutation-a risk for ALL. Nat Rev Clin Oncol 13: 4, 2016.

34. Pauli S, Steinemann D, Dittmann K, Wienands J, Shoukier M, Möschner M, Burfeind P, Manukjan G, Göhring G and Escherich G: Occurrence of acute lymphoblastic leukemia and juvenile myelomonocytic leukemia in a patient with Noonan syndrome carrying the germline PTPN11 mutation p.E139D. Am J Med Genet A 158: 652-658, 2012.

35. Bradley CP, Chen C, Oetjen KA, Yan C, Panjwani R, Hauffe S, Calvo KR, Yuan C, Patel PA, Montgomery ND, et al: Persistence of skewed X-chromosome inactivation in pre-B acute lymphoblastic leukemia of a female ATRX mutation carrier. Blood Adv 3: 2627-2631, 2019.

36. Hoshino A, Okada S, Yoshida K, Nishida N, Okuno Y, Ueno H, Yamashita M, Okano T, Tsumura M, Nishimura S, et al: Abnormal hematopoiesis and autoimmunity in human subjects with germline IKZF1 mutations. J Allergy Clin Immunol 140: 223-231, 2017.

37. Chen C, Bartenhagen C, Gombert M, Okpanyi V, Binder V, Röttgers S, Bradtke J, Teigler-Schlegel A, Harbott J, Ginzel S, et al: Next-generation-sequencing of recurrent childhood high hyperdiploid acute lymphoblastic leukemia reveals mutations typically associated with high risk patients. Leuk Res 39: 990-1001, 2015.

38. Loughran SJ, Kruse EA, Hacking DF, de Graaf CA, Hyland CD, Willson TA, Henley KJ, Ellis S, Voss AK, Metcalf D, et al: The transcription factor erg is essential for definitive hematopoiesis and the function of adult hematopoietic stem cells. Nat Immunol 9: 810-819, 2008.

39. Rehman AU, Rahman MU, Khan MT, Saud S, Liu H, Song D, Sultana P, Wadood A and Chen HF: The landscape of protein tyrosine phosphatase (Shp2) and cancer. Curr Pharm Des 24: $3767-3777,2018$

40. van Scherpenzeel Thim V, Remacle S, Picard J, Cornu G, Gofflot F, Rezsohazy R and Verellen-Dumoulin C: Mutation analysis of the HOX paralogous 4-13 genes in children with acute lymphoid malignancies: Identification of a novel germline mutation of HOXD4 leading to a partial loss-of-function. Hum Mutat 25: 384-395, 2005.

41. Perez-Garcia A, Ambesi-Impiombato A, Hadler M, Rigo I, LeDuc CA, Kelly K, Jalas C, Paietta E, Racevskis J, Rowe JM, et al: Genetic loss of SH2B3 in acute lymphoblastic leukemia. Blood 122: 2425-2432, 2013.

42. Qian M, Cao X, Devidas M, Yang W, Cheng C, Dai Y, Carroll A, Heerema NA, Zhang H, Moriyama T, et al: TP53 germline variations influence the predisposition and prognosis of B-cell acute lymphoblastic leukemia in children. J Clin Oncol 36: 591-599, 2018.

43. Chen L, Xu B, Long X, Gu J, Lou Y, Wang D, Cao Y, Wang N, Li C, Wang G, et al: CAR T-cell therapy for a relapsed/refractory acute B-cell lymphoblastic lymphoma patient in the context of li-fraumeni syndrome. J Immunother Cancer 8: e000364, 2020.

44. Hamadou WS, Abed RE, Besbes S, Bourdon V, Fabre A, Youssef YB, Laatiri MA, Eisinger F, Mari V, Gesta P, et al: Familial hematological malignancies: ASXL1 gene investigation. Clin Transl Oncol 18: 385-390, 2016.

45. Seiter K, Htun K, Baskind P and Liu Z: Acute myeloid leukemia in a father and son with a germline mutation of ASXL1. Biomark Res 6: 7, 2018.

46. Zink F, Stacey SN, Norddahl GL, Frigge ML, Magnusson OT, Jonsdottir I, Thorgeirsson TE, Sigurdsson A, Gudjonsson SA, Gudmundsson $\mathrm{J}$, et al: Clonal hematopoiesis, with and without candidate driver mutations, is common in the elderly. Blood 130: 742-752, 2017.

47. Pan LL, Huang YM, Wang M, Zhuang Xe, Luo Df, Guo Sc, Zhang Zs, Huang Q, Lin Sl and Wang Sy: Positional cloning and next-generation sequencing identified a TGM6 mutation in a large Chinese pedigree with acute myeloid leukaemia. Eur J Hum Genet 23: 218-223, 2015.

48. Hahn CN, Babic M, Schreiber AW, Kutyna MM, Wee LA, Brown AL, Perugini M, Singhal D, Hiwase S, Feng J, et al: Rare and common germline variants contribute to occurrence of myelodysplastic syndrome. Blood 126: 1644, 2015.

49. Abelson S, Collord G, Ng SW, Weissbrod O, Cohen NM, Niemeyer E, Barda N, Zuzarte PC, Heisler L, Sundaravadanam Y, et al: Prediction of acute myeloid leukaemia risk in healthy individuals. Nature 559: 400-404, 2018. 
50. Carter H, Marty R, Hofree M, Gross AM, Jensen J, Fisch KM Wu X, DeBoever C, Van Nostrand EL, Song Y, et al: Interaction landscape of inherited polymorphisms with somatic events in cancer. Cancer Discov 7: 410-423, 2017.

51. Bluteau O, Sebert M,Leblanc T, de Latour RP, Quentin S, Lainey E, Hernandez L, Dalle JH, de Fontbrune FS, Lengline E, et al: A landscape of germ line mutations in a cohort of inherited bone marrow failure patients. Blood 131: 717-732, 2018.

52. Taeubner J, Wieczorek D, Yasin L, Brozou T, Borkhardt A and Kuhlen M: Penetrance and expressivity in inherited cancer predisposing syndromes. Trends Cancer 4: 718-728, 2018.

53. Sabattini E, Bacci F, Sagramoso C and Pileri SA: WHO classification of tumours of haematopoietic and lymphoid tissues in 2008: An overview. Pathologica 102: 83-87, 2010.

54. Drazer MW, Kadri S, Sukhanova M, Patil SA, West AH Feurstein S, Calderon DA, Jones MF, Weipert CM, Daugherty CK, et al: Prognostic tumor sequencing panels frequently identify germ line variants associated with hereditary hematopoietic malignancies. Blood Adv 2: 146-150, 2018.
55. Király AP, Kállay K, Gángó A, Kellner A, Egyed M, Szőke A, Kiss R, Vályi-Nagy I, Csomor J, Matolcsy A and Bödör C: Familial acute myeloid leukemia and myelodysplasia in hungary. Pathol Oncol Res 24: 83-88, 2018.

56. Xiao H, Shi J, Luo Y, Tan Y, He J, Xie W, Zhang L, Wang Y, Liu L, Wu K, et al: First report of multiple CEBPA mutations contributing to donor origin of leukemia relapse after allogeneic hematopoietic stem cell transplantation. Blood 117: 5257-5260, 2011.

57. Galera P, Hsu AP, Wang W, Droll S, Chen R, Schwartz JR, Klco JM, Arai S, Maese L and Zerbe C: Donor-derived MDS/AML in families with germline GATA2 mutation. Blood 132: 1994-1998, 2018. 